\title{
Effectiveness of gefitinib in combination with methotrexate in the treatment of ectopic pregnancy
}

\author{
Perrine Capmas' \\ Hervé Fernandez ${ }^{2}$ \\ 'Inserm, Centre of Research \\ in Epidemiology and Population \\ Health (CESP), ${ }^{2}$ Department of \\ Gynecology, Bicetre Hospital, GHU \\ Sud, AP-HP, Le Kremlin Bicêtre, France
}

Correspondence: Perrine Capmas Department of Gynecology, Bicetre Hospital, 78 avenue du Général Leclerc, 94275, Le Kremlin Bicêtre, France Tel +33 | 452 2। 77 ।4

Email perrine.capmas@bct.aphp.fr
This article was published in the following Dove Press journal:

International Journal of Women's Health

3 July 2015

Number of times this article has been viewed
Abstract: Medical management for ectopic pregnancy is subject to substantial variations with different protocols and various routes of administration. Regardless the protocol used, methotrexate is currently the medical treatment of choice for ectopic pregnancy. The risk of a rescue surgery is a main concern. Recently, some studies suggested combining gefitinib and methotrexate to improve medical treatment and to decrease the need for reinjection and for additional surgery. Gefitinib is an orally administered EGF receptor-tyrosine kinase inhibitor. For tubal ectopic pregnancy, median recovery time was shorter after combination treatment with gefitinib and methotrexate. Toxicity reported with combination treatment was acneiform rash in $67 \%$ of cases and diarrhea in $42 \%$. They were always transient and are known side effects of gefitinib previously described in lung cancer. These preliminary results are very promising but need to be explored further before wide distribution. For ectopic pregnancy, combining treatment seems to be interesting but results of the first randomized trial have to be evaluated first. For other indications, such as non-tubal ectopic pregnancy or choriocarcinoma, randomized studies are needed before wide use of the combination in current practice.

Keywords: toxicity, efficacy, EGF receptor-tyrosine kinase inhibitor, non-tubal ectopic pregnancy

\section{Introduction}

Ectopic pregnancy occurs in $1.5 \%-2 \%$ of all pregnancies. ${ }^{1}$ Four different management strategies for ectopic pregnancy may be considered: expectant management (follow-up until decrease of human chorionic gonadotropin [HCG] rate), medical treatment, conservative surgery, and radical surgery. Nonetheless, care for women with ectopic pregnancies remains a topic of debate, and no consensus or guidelines exist to clarify the choice between different treatments. ${ }^{2}$ Activity of ectopic pregnancy (allowing to differentiate between ectopic pregnancies that can benefit from a medical treatment and those requiring a surgical management) is probably the major concept to decide the most appropriate treatment. ${ }^{3}$ This concept is well recognized and generally applied to determine which ectopic pregnancies could benefit from medical treatment. Nonetheless, the definition of activity is also not consensual; decision criteria are different from one study to another. Even for initial rate of HCG, the decision thresholds are not the same between studies.

Earlier diagnosis and better access to care leads to the possibility of medical treatment in many cases. Medical management for ectopic pregnancy is subject to substantial variations with different protocols and various routes of administration. Regardless the protocol used, methotrexate is currently the medical treatment of choice for ectopic pregnancy. Sometimes, several injections are required to recover. Finally, the use of 
surgical management to recover is needed in 10\%-25\% of cases after medical treatment with methotrexate. ${ }^{4-8}$ This risk of a rescue surgery is a main concern. Recently, some studies suggested combining gefitinib and methotrexate to improve medical treatment and to decrease the need for reinjection and additional surgery..$^{9,10}$

The aim of this review is to evaluate efficacy and safety of gefitinib in combination with methotrexate in different indications such as tubal and non-tubal ectopic pregnancy and also to report tolerance of this combination, the need for additional injection of methotrexate, and rates of additional surgery.

\section{Medical treatment of ectopic pregnancy}

Tanaka et al reported the first use of methotrexate as medical treatment for ectopic pregnancy in $1982 .{ }^{11}$ Methotrexate is an antimetabolite that acts by actively proliferating cells, including trophoblastic tissue. The dose of methotrexate used in ectopic pregnancy is $1 \mathrm{mg} / \mathrm{kg}$ or $50 \mathrm{mg} / \mathrm{m}^{2}$. This treatment can be injected intramuscularly or directly into the ectopic pregnancy under sonographic guidance. ${ }^{12}$ Some protocols advocate the use of a single injection with rescue injection if necessary, whereas other protocols recommend the use of two, three, or four systematic injections every other day. ${ }^{7,13,14}$ There are no studies comparing all these protocols for efficacy, rate of additional surgery, and safety (rate of side effects). Barnhart et al compared "single dose" and "multi-dose" protocols and concluded that "single dose" protocol was less effective, but was also associated with fewer side effects. A comparison to a two-dose regimen should be done. ${ }^{15}$ In all published studies, the rate of additional surgery to recover after methotrexate injection is $10 \%-25 \%{ }^{4-8}$ Reported side effects are minor and transient, mainly abdominal pain, asymptomatic elevation of liver enzyme, and in rare cases (approximately 1\%) transient hepatitis has been reported. ${ }^{6}$

\section{Gefitinib}

Gefitinib is an orally administered EGF (epidermal growth factor) receptor-tyrosine kinase inhibitor used in breast cancer and non-small-cell lung cancer. ${ }^{16-18}$ It is a drug that selectively inhibits the tyrosine kinase domain of the EGF receptor and blocks signal transduction pathways implicated in the proliferation and survival of cancer cells. ${ }^{19}$ Normal human placenta expresses very high levels of EGF receptor, more than 30 times higher than average tissue expression. It has the highest expression of EGF receptor compared to all other non-malignant tissues. ${ }^{20}$ The presence of receptors in the placenta of an ectopic pregnancy has also been confirmed $^{21}$ specifically on the outer membrane of the syncytiotrophoblast.

\section{Effects of gefitinib}

Preclinical studies were performed to evaluate combination of methotrexate and gefitinib compared to methotrexate alone and gefitinib alone for inhibition of placental cell growth. Inhibition of placental cell growth by methotrexate alone is dose dependent and gefitinib alone had little effect on placental cell growth. In contrast, methotrexate with increasing concentration of gefitinib had a potent additive effect. This study also demonstrated that combination of methotrexate and gefitinib not only inhibited cell growth but also induced cell death. ${ }^{21}$

In in vivo studies on mice with subcutaneous human placental cells on one hand and intrauterine early pregnancy on the other hand, a dose dependent response to methotrexate alone was observed similarly to gefitinib alone, but not with in vitro models. The use of both treatments together significantly increased response compared to methotrexate alone or to gefitinib alone. ${ }^{21}$

\section{Efficacy}

Twelve women with ectopic pregnancy were included in a Phase I study treated with methotrexate $\left(50 \mathrm{mg} / \mathrm{m}^{2}\right.$, intramuscularly) and gefitinib (250 mg orally on day 1 for three women, three times on day 1, 2, and 3 for three women, and seven times on day 1, 2, 3, 4, 5, 6, and 7 for six women). Ten out of 12 women's (83\%) ectopic pregnancies resolved with the combination of methotrexate and gefitinib and one out of ten needed a rescue methotrexate injection. Compared to 71 historic controls treated with methotrexate alone, HCG levels by day 4 and by day 7 after treatment among women treated with combination treatment were significantly lower $(P<0.05)$ and median recovery time was 11 days shorter in this group $(P=0.02){ }^{10}$

A Phase II open multi-center clinical trial has been conducted to evaluate efficacy of a combination of gefitinib (250 mg orally, daily for 7 days) and methotrexate $\left(50 \mathrm{mg} / \mathrm{m}^{2}\right.$, intramuscularly) in the treatment of ectopic pregnancy. The study protocol was published in 2013; results should be readily available. ${ }^{9}$

For non-tubal ectopic pregnancy, Horne et al published a case series of non-tubal ectopic pregnancies treated with methotrexate and gefitinib. Eight women were included in this study, five with interstitial ectopic pregnancies and three 
with cesarean scar ectopic pregnancies. No surgical treatment was required and five women out of eight required a second methotrexate injection (three of them because of a significant rise in serum HCG between days 1 and 4; the two others because serum HCG had not fallen more than $15 \%$ between days 4 and 7). ${ }^{22}$

\section{Safety}

In a Phase I study comparing 12 women treated with the combination of methotrexate and gefitinib to 71 historic controls treated with methotrexate alone, toxicity reported with combination treatment was acneiform rash in $67 \%$ of cases and diarrhea in $42 \% .{ }^{10}$ They were always transient and are known side effects of gefitinib previously described in lung cancer. ${ }^{23}$ No clinical or biochemical evidence of serious side effects (eg, renal, hepatic, pulmonary, or hematologic toxicity) was recorded.${ }^{10}$ Horne et al have reported the same side effects in addition to dizziness with combination of methotrexate and gefitinib in non-tubal ectopic pregnancy. ${ }^{22}$ These results have yet to be confirmed in a Phase II trial; the protocol of such study has already been published, results are expected. ${ }^{9}$

\section{Discussion}

These preliminary results are very promising but need to be explored further before wide distribution. Interest of gefitinib in treatment of tubal ectopic pregnancy begins to be demonstrated. However, if efficacy of medical treatment improves with this combination, indications could expand. The major point of interest of this combination is the increase in success of medical treatment alone, the diminution of rescue injection of methotrexate, the reduction of healing time, and the cost saving that could be generated. Reduction in healing time avoids the need for repeat HCG blood samples until recovery; increased success of medical treatment alone limits hospitalization and surgery; and diminution of rescue injection of methotrexate also reduces costs.

Other points should be explored such as evaluation of combination of in situ methotrexate and gefitinib. A retrospective study suggests a superiority of intramuscular route. ${ }^{12}$ This route might also be enhanced by gefitinib.

Systematic postoperative injection of methotrexate has also been debated because of its efficacy weighed against the risk of side effects. ${ }^{24-26}$ As gefitinib seems to be well tolerated, it should be interesting to use it after conservative surgery (salpingotomy) to avoid persistent trophoblasts. This indication has to be evaluated for efficacy and safety.
Another real challenge is to improve medical management of non-tubal ectopic pregnancy, which presents an important hemorrhagic risk. The preliminary results of Horne et al about the use of methotrexate and gefitinib in the management of non-tubal ectopic pregnancy are very encouraging and should be developed to enable use in clinical practice. ${ }^{22}$

Rates of subsequent fertility after medical management and conservative surgery seem to be similar according to a randomized trial, ${ }^{6}$ but the combination of methotrexate and gefitinib should not only be evaluated comparing medical treatment with methotrexate but also with conservative surgery. Effects of gefitinib on a fetus during the next pregnancy should also be evaluated.

Finally, choriocarcinoma might be another medical condition that could be treated with the combination of both drugs.

\section{Conclusion}

Combination of gefitinib and methotrexate might be the future for medical treatment of ectopic pregnancy. However, Phase II and Phase III studies have to be conducted before large utilization. For other indications, such as non-tubal ectopic pregnancy or choriocarcinoma, randomized studies are needed before wide use of the combination in current practice.

\section{Disclosure}

The authors have no conflicts of interest to disclose.

\section{References}

1. Chang J, Elam-Evans LD, Berg CJ, Herndon J, Flowers L, Seed KA, et al Pregnancy-related mortality surveillance - United States, 1991-1999. Morbidity and mortality weekly report Surveillance summaries. 2003;52(2):1-8

2. Farquhar CM. Ectopic pregnancy. Lancet. 2005;366(9485):583-591.

3. Capmas P, Bouyer J, Fernandez H. Treatment of ectopic pregnancies in 2014: new answers to some old questions. Fertility and Sterility. 2014; 101(3):615-620.

4. de Bennetot M, Rabischong B, Aublet-Cuvelier B, Belard F, Fernandez H, Bouyer J, et al. Fertility after tubal ectopic pregnancy: results of a populationbased study. Fertility and Sterility. 2012;98(5):1271-1276.e1-3.

5. Fernandez H, Capella-Allouc S, Audibert F. Success rates of methotrexate in ectopic pregnancy? Fertility and Sterility. 1998;70(3):596-597.

6. Fernandez H, Capmas P, Lucot JP, Resch B, Panel P, Bouyer J. Fertility after ectopic pregnancy: the DEMETER randomized trial. Hum Reprod. 2013;28(5):1247-1253.

7. Hajenius PJ, Engelsbel S, Mol BW, Van der Veen F, Ankum WM, Bossuyt PM, et al. Randomised trial of systemic methotrexate versus laparoscopic salpingostomy in tubal pregnancy. Lancet. 1997; 350(9080):774-779.

8. Sowter MC, Farquhar CM, Petrie KJ, Gudex G. A randomised trial comparing single dose systemic methotrexate and laparoscopic surgery for the treatment of unruptured tubal pregnancy. Bjog. 2001;108(2):192-203. 
9. Horne AW, Skubisz MM, Doust A, Duncan WC, Wallace E, Critchley HO, et al. Phase II single arm open label multicentre clinical trial to evaluate the efficacy and side effects of a combination of gefitinib and methotrexate to treat tubal ectopic pregnancies (GEM II): study protocol. BMJ Open. 2013;3(7).

10. Skubisz MM, Horne AW, Johns TG, Nilsson UW, Duncan WC, Wallace EM, et al. Combination gefitinib and methotrexate compared with methotrexate alone to treat ectopic pregnancy. Obstetrics and Gynecology. 2013;122(4):745-751.

11. Tanaka T, Hayashi H, Kutsuzawa T, Fujimoto S, Ichinoe K. Treatment of interstitial ectopic pregnancy with methotrexate: report of a successful case. Fertility and Sterility. 1982;37(6):851-852.

12. Nazac A, Gervaise A, Bouyer J, de Tayrac R, Capella-Allouc S, Fernandez H. Predictors of success in methotrexate treatment of women with unruptured tubal pregnancies. Ultrasound Obstet Gynecol. 2003;21(2):181-185.

13. Stovall TG, Ling FW, Gray LA. Single-dose methotrexate for treatment of ectopic pregnancy. Obstetrics and Gynecology. 1991;77(5): 754-757.

14. Barnhart K, Hummel AC, Sammel MD, Menon S, Jain J, Chakhtoura N. Use of "2-dose" regimen of methotrexate to treat ectopic pregnancy. Fertility and Sterility. 2007;87(2):250-256.

15. Barnhart KT, Gosman G, Ashby R, Sammel M. The medical management of ectopic pregnancy: a meta-analysis comparing "single dose" and "multidose" regimens. Obstetrics and Gynecology. 2003;101(4): $778-784$.

16. Anandappa G, Turner NC. Targeting receptor tyrosine kinases in HER2negative breast cancer. Current Opinion in Oncology. 2013;25(6): 594-601.

17. Herbst RS, Fukuoka M, Baselga J. Gefitinib - a novel targeted approach to treating cancer. Nature Reviews Cancer. 2004;4(12):956-965.

18. Herbst RS, Giaccone G, Schiller JH, Natale RB, Miller V, Manegold C, et al. Gefitinib in combination with paclitaxel and carboplatin in advanced non-small-cell lung cancer: a phase III trial - INTACT 2. Journal of Clinical Oncology: official Journal of the American Society of Clinical Oncology. 2004;22(5):785-794.
19. Herbst RS, Kies MS. Gefitinib: current and future status in cancer therapy. Clinical Advances in Hematology and Oncology: H\&O. 2003;1(8): 466-472.

20. Ferretti C, Bruni L, Dangles-Marie V, Pecking AP, Bellet D. Molecular circuits shared by placental and cancer cells, and their implications in the proliferative, invasive and migratory capacities of trophoblasts. Human Reproduction Update. 2007;13(2):121-141.

21. Nilsson UW, Johns TG, Wilmann T, Kaitu'u-Lino T, Whitehead C, Dimitriadis E, et al. Effects of gefitinib, an epidermal growth factor receptor inhibitor, on human placental cell growth. Obstetrics and Gynecology. 2013;122(4):737-744.

22. Horne AW, Skubisz MM, Tong S, Duncan WC, Neil P, Wallace EM, et al. Combination gefitinib and methotrexate treatment for nontubal ectopic pregnancies: a case series. Hum Reprod. 2014;29(7): 1375-1379.

23. Govindan R, Natale R, Wade J, Herbst R, Krebs A, Reiling R, et al. Efficacy and safety of gefitinib in chemonaive patients with advanced non-small cell lung cancer treated in an Expanded Access Program. Lung Cancer. 2006;53(3):331-337.

24. Graczykowski JW, Mishell DR Jr. Methotrexate prophylaxis for persistent ectopic pregnancy after conservative treatment by salpingostomy. Obstetrics and Gynecology. 1997;89(1):118-122.

25. Akira S, Negishi Y, Abe T, Ichikawa M, Takeshita T. Prophylactic intratubal injection of methotrexate after linear salpingostomy for prevention of persistent ectopic pregnancy. The Journal of Obstetrics and Gynaecology Research. 2008;34(5):885-889.

26. Hajenius PJ MF, Mol BW, Bossuyt PM, Ankum WM, Van der Veen F. Interventions for tubal ectopic pregnancy. Cochrane database of systemic reviews. 2007;(1):CD000324.
International Journal of Women's Health

\section{Publish your work in this journal}

The International Journal of Women's Health is an international, peerreviewed open-access journal publishing original research, reports, editorials, reviews and commentaries on all aspects of women's healthcare including gynecology, obstetrics, and breast cancer. The manuscript management system is completely online and includes

\section{Dovepress}

a very quick and fair peer-review system, which is all easy to use Visit http://www.dovepress.com/testimonials.php to read real quotes from published authors. 